\title{
Memory Disjunctivism: a Causal Theory
}

\author{
Alex Moran ${ }^{1}$ \\ Accepted: 29 June 2021/Published online: 6 September 2021 \\ (C) The Author(s) 2021
}

\begin{abstract}
Relationalists about episodic memory must endorse a disjunctivist theory of memory-experience according to which cases of genuine memory and cases of total confabulation involve distinct kinds of mental event with different natures. This paper is concerned with a pair of arguments against this view, which are analogues of the 'causal argument' and the 'screening off argument' that have been pressed in recent literature against relationalist (and hence disjunctivist) theories of perception. The central claim to be advanced is that to deal with these two arguments, memory disjunctivists both can and should draw on resources that are standardly appealed to by rival common factor theories of episodic memory, and, in particular, to the idea that genuine memories and merely apparent ones are to be distinguished, at least in part, in terms of the distinctive ways in which they are caused. On the proposed view, there are substantive causal constraints associated both with cases of genuine memory and with cases of mere confabulation. The resulting theory thus tells us something important about the nature both of genuine memories and of mere confabulations, namely, that such experiences must be caused in certain distinctive ways and cannot occur except as the result of a distinctive sort of causal process. In addition, the theory enables the disjunctivist to offer a unified response to an important pair of arguments against her view.
\end{abstract}

Keywords Memory $\cdot$ Disjunctivism $\cdot$ Relationalism $\cdot$ Causal theory

Alex Moran

alexander.moran@philosophy.ox.ac.uk

1 Philosophy Department, University of Oxford (University College), Oxford, UK 


\section{Introduction}

According to the relational theory of memory, genuine memories are relational states of affairs consisting in the acquaintance relation obtaining between the remembering subject and an event she once experienced. ${ }^{1}$ In cases of total confabulation, however, the experiencing subject is not acquainted with any past event. ${ }^{2}$ Consequently, relationalists must endorse a disjunctive theory of episodic memory, on which cases of genuine memory and cases of mere confabulation involve distinct kinds of mental event with different natures. In cases of genuine memory, the relevant experience has a past event that the subject once experienced as a constituent. In cases of total confabulation, by contrast, this is not so, and hence confabulatory experiences must be given a different analysis. ${ }^{3,4}$

This aim if this paper is not to motivate disjunctivism. Rather, I take it to be a view well worth taking seriously, and am concerned here instead with two related challenges to it, which are analogues of the 'casual argument' and the 'screening off argument' that have been pressed in recent literature against the relationalist (and hence disjunctivist) theory of perception. ${ }^{5}$ The first part of the paper sets out these two arguments against the memory disjunctivist (sections 2 and 3). The second part then develops a novel and unified response to these two arguments on the memory disjunctivist's behalf (sections 4 and 5). The central claim to be advanced is that to reply to these two arguments, memory disjunctivists both can and should draw on resources that are already standardly appealed to by traditional common factor theories of memory, and, in particular, to the idea that genuine memories and merely confabulatory ones are to be distinguished, at least in part, in terms of the distinctive ways in which they are caused. On the proposed view, there are substantive causal constraints associated both with cases of genuine memory and with cases of mere confabulation. The theory thus tells us something important about the nature both of genuine memories and of mere confabulations, namely, that such experiences must be caused in certain distinctive ways and cannot occur except as the result of distinctive sorts of

\footnotetext{
${ }^{1}$ A recent advocate of the relational view is Debus (2008); cf. also Martin (2001). Similar views were once defended by Bertrand Russell (1912) and William Earle (1956).

${ }^{2}$ Here and throughout I am concerned with cases of total confabulation, rather than mixed cases wherein the subject is partly remembering but also partly confabulating (but see fn. 29). N.b., I am using the word 'total confabulation' to pick out what is roughly the analogue of the philosopher of perception's notion of a 'total hallucination', rather than some other usage. For relevant discussion here of some relevant distinct notions of confabulation see Robins 2020.)

${ }^{3}$ An important question for relationalists, therefore, concerns the nature of the merely confabulatory sort of experience. So far, relationalists about memory have be silent about this issue; however, if relationalists are to end up with a total disjunctivist theory of memory, then this question must be addressed. (An analogous point applies to relationalists about perception who must hold a disjunctive theory of sense-experience cf. Dancy 1995; Sturgeon 1998; Moran 2019a).

${ }^{4}$ Advocates of a non-standard representationalist theory of memory, on which genuine memories are taken to involve object-dependent contents of a kind that could not be involved in total confabulation, also end up committed to disjunctivism, and therefore also face the two main arguments that I discuss here. (Cf. recent discussions of 'disjunctivist intentionalism' in the perception literature, e.g., McDowell 1994; Logue 2015; Soteriou, 2005; Tye 2007, 2009, 2014; Pautz manuscript). It is thus worth noting that the 'causalist' response to these arguments that I develop here on behalf of the relationalist can also be developed in a representationalist setting.

${ }^{5}$ Recent defences of a relational (and hence disjunctivist) theory of perception include, among others, Brewer (2011); Campbell (2002); Fish (2009); Martin (2004, 2006).
} 
causal process. In addition, the proposed view enables the disjunctivist to offer a unified response to an important pair of arguments against her view.

\section{The Causal Argument}

In light of their commitment to disjunctivism, relational theories of memory face an argument analogous to the 'causal argument from hallucination' that has been pressed against relationalist theories of perception. ${ }^{6} \mathrm{We}$ might refer to this as the 'causal argument from confabulation'. ${ }^{7}$ It relies on two main premises:

Proximate Causes

For every genuine memory experience, $m$, there is a nomically possible confabulatory experience, $c$, with the same proximate cause as $m$.

And,

\section{Same Cause, Same Effect}

If an event of kind $\mathrm{A}$ is the proximate cause of an event of kind $\mathrm{B}$, then, it is nomically necessary that whenever an event of kind A occurs, it produces an effect of kind $\mathrm{B}$ as its immediate effect.

Both premises are plausible. Jointly, however, they imply that the disjunctivist theory of memory is false. Consider the following argument. In cases of total confabulation, there is no past event with which one is acquainted. For memory disjunctivists, however, genuine memories constitutively involve acquaintance with past events. Accordingly, such theorists must deny that one can be have the sort of experience involved in genuine memory in merely confabulatory cases. By Proximate Causes, however, we can imagine a memory experience $m$ and a confabulatory experience $c$ with the same proximate cause. Therefore, by Same Cause, Same Effect, we can infer that an experience of the same kind as $m$ will be produced by the brain state that produces $c$. This, however, implies that one could have the sort of experience involved in genuine memory in a merely confabulatory case, contrary to what disjunctivists must say.

To reply to this argument, disjunctivists must reject either Proximate Causes or Same Cause, Same Effect. It seems to me, however, that they should accept Proximate Causes. In general, it is plausible to think that psychological states and events, including memories (both real and apparent), have antecedent neural causes. ${ }^{8}$ Given that, however, it seems easy to imagine, for each genuine memory, a merely

\footnotetext{
${ }^{6}$ For classic presentations of the causal argument from hallucination see Foster (1986, 2000); Robinson (1985, 1994). A version of the argument from confabulation is discussed in Bernecker (2008).

${ }^{7}$ To be maximally clear in what follows, I throughout draw a distinction between "the sort of experience involved in genuine memory" and the "genuine memories themselves", the difference being that, e.g. on a common factor view the sort of experience involved in genuine memory need not always be a genuine memory since it might occur in a case of confabulation. Likewise, and for the same reasons, I distinguish "the sort of experience involved in mere confabulation" from an actual "mere confabulation". The reader should keep this in mind as we continue. On the importance of drawing this crucial kind of distinction cf. Johnston (2004).

${ }^{8}$ This thesis is a plausible extension of Martin's (2004: 39-40) thesis of 'Experiential Naturalism', i.e. the doctrine that 'our sense experiences, like other events or states within the natural world, are subject to the causal order, and in this case are thereby subject just to broadly physical causes (i.e. including neurophysiological causes and conditions)...'
} 
confabulatory experience that has an antecedent neural cause of the same kind. Presumably, such token neural causes would have importantly different aetiologies. However, they could well be neural causes of the same type. ${ }^{9}$

If that is right, then to push back against the causal argument, memory disjunctivists should challenge Same Cause, Same Effect. Later on, I develop a response that does just that (see section 5). First, however, it is worth flagging a version of this move that will not work. In the perception literature, relationalists about perception tend to respond to the causal argument from hallucination by criticising Same Cause, Same Effect on the grounds that it rules out the existence of relational effects of a certain kind, namely relational effects one of whose relata need not exist just in virtue of the existence of the relevant kind of proximate cause (Campbell: 2010: §§3-4; Nudds 2013: 274-275; Langsam, 1997: 42-46; Martin 2004: 56-58; 2006: 268-371; McDowell 2010; Travis 2011). What relationalists about perception claim is that perceptual experiences consist in the relation of acquaintance obtaining between subjects and external objects of awareness. For such relationalists, therefore, genuinely perceptual experiences can occur only given that there exists a suitable object of perception. Moreover, no mere proximate brain state could guarantee that this condition is met. The relationalist about perception can therefore object to Same Cause, Same Effect on the basis that it wrongly rules out the kind of relational effect that she takes to be involved in genuine perception. The present thought I want to consider is that in the same way, the memory disjunctivist might object to Same Cause, Same Effect on the grounds that genuine memories constitutively involve acquaintance with past events, but that no mere brain state could guarantee that a suitable past event exists - meaning that no such brain state could be sufficient to produce a genuine memory, contrary to what Same Cause, Same Effect implies.

It should be granted, I think, that this reply would undermine the causal argument in its original form. After all, insisting on the Same Cause, Same Effect principle at this stage would seem to beg the question against any disjunctivist view, including relationalist views of both memory and perception, that recognises the existence of genuinely relational effects. Unfortunately, however, the causal argument, both from hallucination and from confabulation, can be patched up by appealing to cases of veridical hallucination/veridical confabulation. ${ }^{10}$ To see this, consider the following weaker version of the causal principle:

\footnotetext{
${ }^{9}$ In the perception literature, there are relationalists who have challenged the idea that a perception and an hallucination might have the same kind of proximate cause on the basis that genuinely perceptual experiences should be considered as temporally extended events which have as proximate causes, not local neural states of subjects, but rather events involving the external object the subject perceives (see Child, 1992; Johnston 2004; Snowdon 2005). In principle, moreover, the memory disjunctivist could make an analogous move. However, there are at least two important worries to consider. First, the view that the aforementioned relationalists about perception have defended is problematic in and of itself, since it implies that when we see or sense temporally distant objects, our perceptual experiences last much longer than it is plausible to think (see Moran 2019b: 222; cf. Dretske, 1969: 72; Martin 1992: 186). But also, second, it seems obvious that the analogous move in the case of episodic memory cannot succeed. Suppose that I remember an event $e$, at time $t$, whereby $e$ occurred ten years prior to $t$. If we said that the proximate cause of my memory of $e$ were some event involving $e$ itself, or perhaps involving my original experience of $e$, then my memory-experience of $e$ would begin at the same time as $e$ occurred (or that my experience of $e$ occurred). But this is false: by hypothesis, the remembered event $e$ (and my experience of it) occurred ten years prior to the event of me remembering that $e$ took place. I submit, therefore, that memory disjunctivists should grant that memory-experiences (both real and apparent) have local neural causes and that Proximate Causes is true.

${ }^{10}$ For classic discussions of the phenomenon of 'veridical hallucination' see Grice (1961); Lewis (1980). On 'veridical confabulation' see for example Bernecker (2017a); Michaelian (2016).
} 


\section{Same Cause, Same Effect*}

If an event of kind $\mathrm{A}$ is the proximate cause of an event of kind $\mathrm{B}$, then it is nomically necessary that if an event of kind A occurs in some context $\mathrm{C}$, such that in $\mathrm{C}$, all of the background conditions on a kind-B effect occurring are met, the kind-A event will produce a kind-B event as its immediate effect.

Essentially, the response to the causal argument that we are presently considering rejects Same Cause, Same Effect by claiming that since certain effects have background conditions on their instantiation (e.g. the existence of the right kind of external object of sense or the right kind past event), sameness of proximate cause is insufficient for sameness of effect. The revised version of the principle, however, cannot be rejected on those grounds, since it allows that there can be events with substantive background conditions on their instantiation. Moreover, the revised version of the principle is rather plausible. If an event of kind A produces an event of kind $B$, it seems to follow that events of kind $A$ have the power to produce type-B events as their immediate effects. Granted, this might be a conditional power, which can be exercised only when the relevant background conditions on a type-B event occurring are satisfied. However, in cases where those conditions are in fact satisfied, it is hard to see how the type-A event should fail to exercise its power to produce a type-B event. It appears, therefore, that there is good reason to accept the weaker principle (cf. Martin 2004; Nudds 2013).

The weaker principle, however, still causes trouble for disjunctivists, both about perception and about memory. Consider first the case of perception. A disjunctivist about perception will insist that a genuinely perceptual experience can only occur if there exists a suitable external object of sense that is available to be perceived, i.e., she takes this to be a background condition that must be met if a perceptual experience is to occur. Consider, however, a perception $p$ and an hallucination $h$, whereby $h$ is a veridical hallucination (e.g. $h$ might be an hallucination as of a red apple in the presence of an actual red apple). By Proximate Causes, we can suppose that $p$ and $h$ have the same proximate cause. And by Same Cause, Same Effect*, we know that like proximate causes produce like immediate effects whenever the relevant background conditions are met. Moreover, we know that in the case of veridical hallucination, the relevant background condition is met, i.e. there is a suitable external object and it is available to be perceived. Thus, it seems to follow that the neural event that causes $h$ will also produce an experience of the perceptual kind. However, the disjunctivist has to deny this, since in hallucination, whether veridical or otherwise, we don't perceive external things, and hence we do not have experiences of the kind that according to the disjunctivist are involved in cases of genuine perception.

The same problem arises for the memory disjunctivist once we consider cases of veridical confabulation. The memory disjunctivist can rightly insist that on her view, a genuine episodic memory can occur only if there exists in the subject's past a suitable event she once experienced. However, we can imagine a pair of experiences $m$ and $c$, such that $m$ is a genuine memory and $c$ is a veridical confabulation. By Proximate Causes, we can suppose that $m$ and $c$ have the same proximate cause. By Same Cause, Same Effect*, we know that like 
proximate causes produce like immediate effects whenever the relevant background conditions are met. Moreover, we know that in the case of veridical confabulation, the background condition that the memory disjunctivist believes is operative is met, i.e. there does exist a suitable event located in the subject's personal past that is available to be remembered. Accordingly, it seems to follow that the neural event that causes $c$ will also produce an experience of the same kind as $m$. However, the memory disjunctivist must deny this. After all, in cases of mere confabulation, whether veridical or otherwise, the subject is not actually remembering some past event. Therefore, she cannot be having the kind of experience that the memory disjunctivist takes to be involved in genuinely remembering, namely an experience that constitutively involves acquaintance with a past event.

One way to capture all of this is to say that the revised causal argument in effect relies on three main premises, namely Proximate Causes, Same Cause, Same Effect*, and then the following further claim, namely:

Event Condition

The only background condition that must be met for an experience of the kind involved in genuine memory is for a suitable past event to exist.

Given Proximate Causes, Same Cause, Same Effect*, and Event Condition, it follows that in cases of veridical confabulation, the subject will undergo an experience of the kind involved in genuine memory. Disjunctivism, however, implies that one never undergoes the kind of experience involved in genuine memory during a case of total confabulation, whether veridical or otherwise. Accordingly, we can conclude that Proximate Causes, Same Cause, Same Effect*, and Event Condition jointly imply that disjunctivism is false.

The upshot, I submit, is that in order to properly resist the causal argument from confabulation, the memory disjunctivist must do more than just reject Same Cause, Same Effect. In addition, it seems that she must reject Event Condition. More exactly, what she must do is to locate a further background condition on undergoing the sort of experience involved in genuine memory, such that this condition cannot be met in cases of (either veridical or non-veridical) confabulation. Only then will she able to rule out the concern that the sort of experience involved in genuine memory might occur even during total confabulation. ${ }^{11}$

Later in the paper, I develop a causalist version of memory disjunctivism that has precisely this consequence (sections 4 and 5). Before getting to that, however, I want to set out the second, related, argument that memory disjunctivists face. Again, this is a direct analogue of the 'screening off argument' that arises for those who hold a disjunctivist view about perception.

\footnotetext{
${ }^{11}$ Likewise, it follows that disjunctivists about perception must locate a further background condition on undergoing the sort of experience involved in genuine memory, beyond the condition that a suitable external object of sense has to exist and be available to be perceived, such that this condition is not met in cases of either veridical or non-veridical hallucination. Elsewhere, I develop a causalist form of perception disjunctivism that has this consequence, which parallels the causalist account of memory developed here Moran 2019a, manuscript-a.
} 


\section{The Screening off Argument}

The screening off argument against memory disjunctivism proceeds in two main steps. ${ }^{12}$ The first stage aims to establish that even in cases of genuine memory, the subject undergoes the sort of experience involved in pure confabulation. This claim is strictly speaking compatible with memory disjunctivism, since there is logical space for claiming that in cases of genuine memory one undergoes two different kinds of memory-experience, namely, a genuine memory consisting in acquaintance with a past event, and a merely confabulatory experience which does not consist in acquaintance with past event and which instead has some other nature. The second step, however, argues that this position is unstable, and, therefore, that if indeed one undergoes the kind of experience involved in pure confabulation even in cases of genuine memory, then memory disjunctivism is false. Accordingly, the argument can be represented as follows:

1. Even in cases of genuine memory, one undergoes the kind of experience involved in total confabulation.

2. If one undergoes the kind of experience involved in mere confabulation even in cases of genuine memory, then memory disjunctivism is false.

\section{$\therefore$ Memory disjunctivism is false.}

The argument for premise 1 turns once again on Proximate Causes and on the weakened causal principle, Same Cause, Same Effect*. It also draws on one further premise, to the effect that nothing more is required, in order to produce an experience of the kind involved in mere confabulation, beyond the right kind of proximate neural cause. We might refer to this as further premise as:

No Conditions

To produce an experience of the kind involved in total confabulation, nothing more is required than the right kind of proximate cause.

As we saw in the previous section, memory disjunctivists can plausibly insist that in order to produce the kind of experience involved in genuine memory, more is required than merely producing the right kind of proximate cause: in addition, a suitable event must exist in the personal past of the remembering subject. Whatever mere confabulations are, however, i.e. whatever nature these apparent memories turn out to have, there would appear to be no such substantive background conditions on their instantiation. In this way, total confabulations resemble total hallucinations. As Mike Martin (2004: 58) explains, we intuitively think of hallucinatory experiences as being inner events', and, therefore, as being such that no further condition, beyond the subject being in the right kind of antecedent brain state, must be met in order for such events to be produced (cf. Snowdon 2005: 288). I suggest that in much the same way, confabulatory experiences are naturally thought of as 'inner events'. Whatever nature such

\footnotetext{
12 The screening off argument against relational theories of perception is due originally to Martin (2004, 2006). See also Byrne \& Logue (2008); Fish (2009); Hellie (2013); Moran (2019a).
} 
events turn out to have, it is plausible to think that nothing more is required for their instantiation than an instance of the right kind of local neural cause. ${ }^{13}$

Consider now the following argument. By Same Cause, Same Effect*, we know that like proximate causes produce like immediate effects whenever all the background conditions associated with the relevant effect are met. Moreover, given No Conditions, we know that no background conditions need be met for an experience of the merely confabulatory kind to occur (or, equivalently, that all of the conditions on the occurrence of this kind of event are met in every possible situation.) Hence, we can infer if some brain state $b$ produces an experience of the merely confabulatory kind, then any brain state of the same kind as $b$ will produce an experience of that sort. By Proximate Causes, however, we know that for every genuine memory $m$, there is a merely confabulatory experience $c$ with the same proximate cause. Accordingly, we can infer that in every case of genuine memory, the proximate brain state also produces an experience of the merely confabulatory kind. This establishes that premise 1 is true.

Note again that premise 1 is logically consistent with memory disjunctivism. That is, the memory disjunctivist can coherently maintain that in cases of genuine memory, one undergoes both an experience of the kind involved in confabulation, and the kind that she believes to be involved exclusively in genuine memory (i.e. the kind consisting in acquaintance with past events). ${ }^{14}$ What, then, is the argument for premise 2 ? Why think that if the kind of experience involved in total confabulation is present also in the case of genuine memory, then the position of the memory disjunctivist is thereby undermined?

The argument turns on the thought that once premise 1 is accepted, the memory disjunctivist faces an insurmountable problem involving explanatory exclusion or 'screening off'. Consider a pair of cases: $C$ is one of genuine memory, and $C^{*}$ is one of total confabulation. Say that the subject in $C$ is undergoing an experience of kind $\mathrm{Km}$ (i.e. the kind involved exclusively in genuine memory, and which consists in acquaintance with a past event), and that the subject in $C^{*}$ is undergoing an experience of kind Kc (i.e. the merely confabulatory kind). And focus now on the subject in $C^{*}$. The fact that $\mathrm{S}$ in $C^{*}$ is undergoing this experience is capable of explaining various things. For instance, it can explain the various beliefs that she will form in $C^{*}$ (e.g. that such and such an event happened in her personal past). It will also explain why she ends up with a whole range of related psychological attitudes and associated behaviours (perhaps the past event she

\footnotetext{
${ }^{13}$ One might think that merely confabulatory experiences should be thought of as representational states. Moreover, one might then worry that a suitably externalist view of mental representation will challenge $N o$ Conditions by implying that there are in fact background conditions on having the kind of experience involved in confabulation that go beyond the existence of the right kind of proximate brain state, e.g. that the subject be causally embedded within the right sort of environment. Importantly, however, such conditions could also be met in the case of genuine memory. Yet, as we will see, to block the argument for premise 1, the memory disjunctivist will have to locate a background condition on confabulatory experience that cannot be met in cases of genuine memory. It follows that externalist considerations are insufficient by themselves to undermine the case for premise 1 to be set out in the main text.

${ }^{14}$ Note that there are at least two ways to model this. Let Ks be the kind of experience involved in genuine memory, and $\mathrm{K}^{*} \mathrm{~s}$ the kind of experience involved in total confabulation. One way to make sense of premise 1 being true is for the memory disjunctivist to say that in genuine memory, there is one token experience that falls under both kinds, i.e. that is both a $\mathrm{K}$ and a $\mathrm{K}^{*}$. Another option is to hold that there are two experiences, one of which is $\mathrm{K}$ and the other of which is a $\mathrm{K}^{*}$ (perhaps they also stand in some interesting relation, e.g. parthood). For relevant discussion in the case of perception see Martin (2004: 59), Johnston (2004: 117-118). Note also that for present purposes, we do not need to settle on one interpretation or the other.
} 
seems to remember makes her feel regret, or induces a desire to make certain changes, etc.). Moreover, the fact that the confabulating subject is undergoing an experience of kind Kc will also explain why it phenomenally seems to her as if a certain event happened in her past. But now consider $C$, the case of genuine memory. We are supposing that the subject in $C$ also has an experience of kind $\mathrm{Kc}$ (which follows given premise 1). Accordingly, we can appeal to this fact to explain all of the same things we could explain about $C^{*}$. That is, we can appeal to the fact that the remembering subject is having an experience of the merely confabulatory kind to explain why she ends up with a whole range of psychological attitudes and why she exhibits a whole range of behaviours, as well as explaining why the situation she is in has the phenomenology it does (i.e. why things seem phenomenally to her as they do). The trouble, however, is that this seems to leave no explanatory work for the supposed fact that the remembering subject is having an experience of kind $\mathrm{Km}$ to do-where, again, 'Km' names the kind of memoryexperience which, according to the memory disjunctivist, is said to be relational in nature, and to occur exclusively in cases of genuine memory. In short, it is coherent for the memory disjunctivist to grant that even in the case of genuine memory, the subject has an experience of the confabulatory kind. However, it also seems that this is not ultimately a stable position. For, once it is admitted that the confabulatory kind of experience is involved even in the case of genuine memory, it is hard to see what explanatory work the idea that a further kind of experience that is relational in nature and unique to the genuinely memorial case could do. That is, the confabulatory kind of experience would seem to 'screen off' the relational kind of experience (consisting in acquaintance with a past event) from playing any substantive explanatory role. This then appears to tell strongly against the disjunctivist position. ${ }^{15}$

The memory disjunctivist must reject either premise 1 or premise 2 of the screening off argument. One option, therefore, is to push back against the second premise. In the analogous case of perception, in fact, this is the move that is standardly made (cf. Moran 2019a). In particular, disjunctivists about perception tend to put forward 'deflationary' or 'minimalist' accounts of the nature of the hallucinatory case specifically designed to allow them to accept that even in cases of genuine perception, the subject undergoes the kind of experience involved in hallucination, yet without this entailing that the hallucinatory kind of experience 'screens off' the distinctively perceptual kind of experience (which for the perception disjunctivist consists in acquaintance with external objects of perception) from playing a distinctive explanatory role. ${ }^{16}$ Such accounts, however, have come under a great deal of criticism, and in my view rightly so. One problem is that the kinds of 'deflationary' theory of hallucination that this strategy requires are unattractive in and of themselves (see e.g., Conduct 2010; Burge 2005; Farkas 2006; Hawthorne \& Kovakovich 2006; Moran 2019a; Pautz 2011;

\footnotetext{
${ }^{15}$ Standard 'common factor' theories of memory also allow, of course, that the confabulatory kind of experience is involved in cases of genuine memory. This is because they hold that there is just one kind of mental event involved whether one is genuinely remembering or merely confabulating. However, they do not face an analogous screening off worry. On their view, there is just one kind of experience regardless of whether one is genuinely remembering or confabulating. Whether an instance of this kind of experience is a genuine memory or else a mere confabulation then depends on extrinsic factors such as how the event was caused (cf. section 4).

${ }^{16}$ Proponents of this kind of strategy include Fish (2008, 2009); Johnston (2004); Hellie (2013); Logue (2013a, 2013b); and Martin (2004, 2006, 2013).
} 
Searle 2015; Siegel 2004, 2008; Smith 2008). Another is that even given these 'deflationary' theories of hallucination, it is unclear that the worry about explanatory exclusion really goes away Moran (manuscript-b). There is reason, moreover, to think that these problems would carry over straightforwardly to the case of memory. In principle, then, in a bid to reject premise 2 , the memory disjunctivist could offer a 'deflationary' or 'minimalist' account of the nature of confabulatory experiences, analogous to the accounts of hallucination that some disjunctivists about perception have offered. ${ }^{17}$ However, there will then be the concern that any such account of confabulation is unattractive or problematic in and of itself. Moreover, the worry will arise that even given the relevant theory of confabulatory experience, the screening off problem will still remain.

Accordingly, this paper recommends an alternative strategy. In particular, I recommend rejecting premise 1 . As we have seen, premise 1 follows from three main claims: Proximate Causes, Same Cause, Same Effect*, and No Conditions. Moreover, I have already indicated that memory disjunctivists should accept the first two claims. What I'll be suggesting, however, is that disjunctivists should reject No Conditions. On the view to be developed, there are substantive causal conditions, going beyond the occurrence of the right kind of proximate cause, that must be met if an experience of the confabulatory kind is to occur. The idea, moreover, is that these conditions cannot be met in cases of genuine memory. Given this view, the argument for premise 1 can then be blocked. Indeed, as we will see, the view implies the falsity of premise 1, since it entails that the confabulatory kind of experience simply cannot occur in cases of genuine memory.

\section{Towards a Causalist Disjunctivism}

As we have seen, relationalists about memory must be disjunctivists, i.e. they must deny that genuine memory and mere confabulation involve mental events of the same kind. In the memory literature, however, it is much more common for philosophers to endorse a 'common factor' theory of memory, on which the same kind of mental event is involved in both genuine memory and mere confabulation. Examples of such views include the mental image theory, according to which memory-experiences consist in acquaintance with mental images, as well as the representationalist theory, on which memoryexperiences are to be understood as being a certain kind of representational state. ${ }^{18}$ On views of this kind, regardless of whether one is remembering or confabulating, the experience involved has the same intrinsic nature. That is, cases of genuine memory and cases of mere confabulation involve mental events of precisely the same kind.

\footnotetext{
${ }^{17}$ For instance, Martin $(2004,2006,2013)$ recommends a 'negative epistemic account' of hallucination, on which hallucinatory experiences are nothing more than mental events that can't be told apart by introspection from genuine perceptions. In the same vein, a memory disjunctivist might argue that confabulatory experiences are nothing more than mental events that can't be told apart by introspection from corresponding cases of genuine memory.

18 This is pace Schwarz (2018), who wrongly claims that representationalists are also committed to disjunctivism. Certain non-standard representationalists may end up committed to disjunctivism (cf. fn. 4), but this is not the case for standard representationalists, who hold that the same sort of memory-experience is involved in both genuine memory and total confabulation.
} 
Unlike disjunctivists, proponents of a common factor theory face the following explanatory challenge. Some memory-experiences are genuine memories. Others are mere confabulations. ${ }^{19}$ Yet, on a common factor theory, we cannot explain why this is so in terms of the mental natures of the relevant events. Common factor theorists, therefore, must locate a non-mental difference between memory-experiences that can serve to explain why some are genuine memories (which make subjects aware of past events they once experienced) whereas others are mere confabulations (which do not make subjects aware of past events).

One traditional, and still quite standard, way for common factor theorists to meet this challenge is to appeal to the causal theory of memory. ${ }^{20}$ According to that theory, whether a memory-experience is a genuine memory or else a case of mere confabulation is determined, at least in part, by the manner in which it is caused. In particular, we must distinguish between 'standard' causation, which is the sort involved in genuine memory, and 'deviant' or 'non-standard' causation, which is the sort involved in confabulation. The idea is that when a memory-experience is the product of a standard causal chain, it is a genuine memory, whereas when a memory-experience is the product of a deviant or non-standard causal chain, it is merely confabulatory experience instead. ${ }^{21}$

Begin with the case of genuine memory. In such a case, the subject is aware of a past event she once experienced. What the causal theorist claims is that a part of what it takes for this to be the case is for there to be an appropriate causal connection between the subject's original experience of the remembered event and the experience that constitutes her episodic memory of that event. In such cases, we have 'standard causation', and hence the memory-experience has the property of being a genuine memory. So, when one has a genuine episodic memory, an event of the very same kind might be involved in some merely confabulatory case. However, the confabulatory experience will not stand in the same sort of causal connection to past experience that one once enjoyed, and will for that reason lack the property of being a genuine memory. ${ }^{22}$

\footnotetext{
${ }^{19}$ Note that I am using the term 'memory-experience' such that a given memory-experience might either be a genuine memory or else a mere confabulation. Disjunctivists will therefore claim that there are two distinct kinds of memory-experience, whereas common factor theorists will deny this.

${ }^{20}$ Since causalism is still a standard view among opponents of disjunctivism, it is fair game, it seems to me, for disjunctivists to appeal to causalist claims. However, one should perhaps note that in the recent memory literature, causalism has come under fire from various angles, and in particular from the simulationist camp. One might also worry: can disjunctivists really appeal to causal resources? Didn’t Snowdon (1981) persuade us that that in the perceptual case, at least, disjunctivism and the causal theory are deeply at odds? No. Snowdon, as he makes clear in his Snowdon (1981) and again in his Snowdon (1990), and has also made clear in personal correspondence, was arguing against the claim that the causal theory of perception is a conceptual truth, on the grounds that disjunctivism cannot be ruled out on conceptualist grounds. But that leaves completely open whether elements of the causal theory of perception could be incorporated within a disjunctivist theory of perception (cf., Moran 2019a: fn. 13), and the same is true of the case of memory. Aranyosi 2020 takes issue with this last claim, but I lack space to engage further with this issue here.

${ }^{21}$ The classic defence of this kind of causal theory is Martin \& Deutscher (1966). For a more recent defence of the causalist theory see Bernecker (2008, 2009, 2017b).

${ }^{22}$ What I am calling an 'appropriate' or 'standard' causal chain may involve what some theorists refer to as a 'memory trace'. Notice, however, that this is not essential, nor are we forced, if we wish to appeal to memory traces, to understand them in representationalist terms, i.e. an appeal to memory traces need not presuppose a representationalist view of memory. (The point is an important one, and needs a fuller defence, as an anonymous referee is has pointed out, but here is not the place to do it).
} 
Consider now the case of total confabulation. In such a case, the subject is not aware of a past event she once experienced; she merely seems to be. What the causal theorist claims, moreover, is that part of what it takes for this to be the case is for the subject's experience to have been deviantly or non-standardly caused. The idea, in other words, is that while genuine memories are memory-experiences that are caused in a distinctive way by past experiences of suitable past events, confabulations are memoryexperiences that have instead been produced in a deviant or non-standard way, and hence in a manner that does not connect the subject to a past experience in the kind of way that, for the causal theorist, is involved in cases of genuine memory.

One important source of motivation for the traditional causalist picture involves contrasting genuine memory with veridical confabulation. ${ }^{23}$ Let ' $\mathrm{E}$ 'be an event that subject $\mathrm{S}$ once experienced in her personal past. In situation $C$, we can suppose, $\mathrm{S}$ has a genuine memory of $\mathrm{E}$. In situation $C^{*}$, by contrast, she has a veridical confabulatory experience that is indistinguishable from her experience in $C$. (We are supposing here that $\mathrm{E}$ exists in S's personal past in both $C$ and $C^{*}$.) The question is: what makes it the case that only one of her experiences is a genuine memory, whereas the other is a mere veridical confabulation? In both cases, the relevant event exists, and is a part of S's personal past. So why does $\mathrm{S}$ only remember $\mathrm{E}$ in $C$, and not in $C$ ? That is, why is her memory-experience only a genuine memory of event $\mathrm{E}$ in $C$ and not in $C^{*}$ ?

The causalist has a compelling answer. On her view, the difference is to be explained in causal terms. In both $C$ and $C^{*}$, the subject $\mathrm{S}$ has an experience of the same kind. Moreover, the relevant event, $\mathrm{E}$, is a part of $\mathrm{S}$ 's personal past in both situations. Nonetheless, the causalist asserts, there is room to identify a crucial difference. In $C$, S's memory-experience is appropriately causally connected to some past experience of E. In $C^{*}$, by contrast, this isn't so, and therefore S's memory-experience will have been deviantly caused. The idea, moreover, is that this difference is what serves to explain why $\mathrm{S}$ genuinely remembers $\mathrm{E}$ in $C$ but is merely confabulating in $C^{*}$. The proposed explanation, that is, is that her memory-experience in $C$ is a genuine memory of $\mathrm{E}$ whereas her memory-experience in $C^{*}$ is merely confabulatory, despite the fact that $\mathrm{E}$ is still apart of S's personal past in $C^{*}$, because in $C$, and not in $C^{*}$, S's memoryexperience appropriately caused by S's past experience of $\mathrm{E}$.

In short, the causalist can offer a compelling picture as to how veridical confabulations are possible. In a veridical confabulation, the subject's personal past really is as her memory-experience portrays it as being. Nevertheless, she is confabulating, not remembering. The causalist is able to account for this by noting that genuine memories must be appropriately caused by past experiences of remembered events, and that confabulatory experiences arise when memory-experiences are not caused in this way, but are instead non-standardly produced. On this approach, the explanation as to why veridical confabulations are possible is that there can be memory-experiences that portray the subject's past in an accurate way but which are also non-standardly and so deviantly caused.

There is also a more general way to motivate the causal theory. In cases of genuine memory, one is aware of some past event that one once experienced. A natural thought, moreover, is that in order for this to be so, one has to be appropriately connected to the original experience one had of that event. In other words, it just seems very plausible to

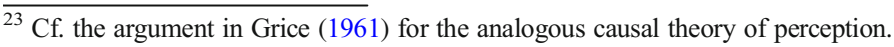


think that this kind of causal connection must be in place to underwrite the fact that one is genuinely remembering some event from one's personal past. In the same way, it seems very natural to think that cases of confabulation arise precisely when this sort of causal connection is absent. When one is suitably causally hooked-up to some past sense-experience of some event, one is thereby able to remember that past event. When one is not suitably causally hooked-up in this manner, however, what results is a confabulatory experience, which is at best indistinguishable from a genuine memory, but which is not itself a case of remembering some event from one's past.

I submit, then, that the causal theory captures something important about the distinction between genuine memory and mere confabulation. In particular, it seems to correctly identify that genuine memories must be appropriately caused by prior experiences of past events, whereas confabulations are the product of deviant causal chains that don't connect the subject to a past experience of an event in her personal past in the right kind of way. However, memory disjunctivists cannot accept the causal theory as it stands, given its commitment to the common factor (and therefore nondisjunctive) conception. The question, then, is whether there is a version of the causal theory that can be held in a disjunctivist setting.

In my view, there is. That is, I think that there is a nearby position to the original causal theory that even disjunctivists can accept. This can be articulated as follows. In cases of genuine memory, one undergoes an experience of a distinctive kind. Such experiences, moreover, must be caused in a specific way. In particular, the sort of experience involved in genuine memory must be produced by a causal chain connecting the subject to a prior experience of an event that is in her personal past. More precisely, the idea is that it lies in the nature of experiences of this kind to be caused in just that way, which then entails that they are necessarily produced in just that way. In other words, the claim is that the kind of experience involved in genuine memory must be produced in the standard way by a suitable past experience of the remembered event because it is an essential feature of events of that kind to be produced in that manner. Similarly, in cases of confabulation, one also undergoes an experience of a distinctive kind. And these experiences, too, must be caused in a specific way. In particular, confabulatory experiences must be generated by a deviant or non-standard causal chain that does not connect the subject in the right way to a past experience of a past event. The idea, moreover, is that it lies in the nature of experiences of this kind to be caused in just that way. That is, such experiences must be non-standardly or deviantly caused because it is an essential feature of events of that kind to be produced in just that manner.

This view, I submit, represents a natural way of accepting something like the traditional causal theory within a disjunctivist setting. There is, however, a crucial difference between the standard causal theory and the above disjunctivist alternative. On the disjunctivist version of the theory, genuine memories are caused in a certain way precisely by virtue of being the kinds of experiences they are, and the same is true for experiences of the confabulatory kind. That is, it lies in the nature, or essence, of genuinely memorial experiences to be caused in one sort of way, and in the nature, or essence, of confabulatory experiences to be caused in another. The traditional causal theory, however, merely specifies the conditions under which instances of one common kind of memory-experience will have one or another extrinsic property, namely that of being a genuine memory/being a mere confabulation. The disjunctivist version of the causal theory, therefore, goes beyond the traditional version, by making claims about 
the respective essences of two experiential kinds, namely the kind involved in genuine memory, and the kind involved in mere confabulation. ${ }^{24}$

Despite this important difference, however, I think a case can be made for thinking that disjunctivists should be attracted to the above kind of causalist view. One way to see this, moreover, is to again consider cases of veridical confabulation, this time within a disjunctivist setting. In situation $C, \mathrm{~S}$ has a genuine memory of $E$. In situation $C^{*}$, by contrast, $\mathrm{S}$ has a veridical confabulatory experience. (The idea, again, is that in both situations, E is an event from S's personal past she once experienced.) Now, the disjunctivist will want to say that two distinct kinds of experience are involved across these cases: in $C$, the subject has a genuinely memorial experience, consisting in acquaintance with $\mathrm{E}$, whereas in $C^{*}$, the subject has an experience that does not consist in acquaintance with any past event. The question, however, is what explains this. In both $C$ and $C^{*}$, the relevant past event, namely $\mathrm{E}$, exists. So why does $\mathrm{S}$ have one kind of experience in $C$, and a quite different kind of experience in $C^{*}$ ? Surely there must be something to explain this fact. So what resources can disjunctivist appeal to?

Given the causal theory sketched above, the disjunctivist can meet this challenge. On the causal theory, it lies in the nature of genuinely memorial experiences to be caused in the standard way by a prior experience of a past event. It also lies in the nature of merely confabulatory experiences to be caused in a deviant or non-standard way. Accordingly, given this theory, the disjunctivist can explain why $\mathrm{S}$ has a genuinely memorial experience in $C$ and yet a merely confabulatory experience in $C^{*}$. In particular, she can insist that while E exists both in $C$ and $C^{*}$, it is only in $C$ that $\mathrm{S}$ 's memory-experience is caused in a suitable way by a prior experience of that event. Because of this, $\mathrm{S}$ has a genuine memory of $\mathrm{E}$ in $C$, and therefore an experience consisting in acquaintance with that remembered event. In $C^{*}$, however, $\mathrm{S}$ 's experience is caused in a deviant way. Accordingly, $\mathrm{S}$ does not have the kind of experience involved in genuine memory. That is, she does not have an experience consisting in acquaintance with a past event. Rather, she has the distinct kind of experience involved in cases of mere confabulation, whatever nature these events turn out to have.

Additionally, the more general way of motivating the causal theory we considered above seems to carry over to a disjunctivist setting. What we noted earlier is that it's very plausible to think that part of what it takes to genuinely remember a past event is for there to be a suitable causal connection to one's past experience of it, and that likewise, it seems very natural to hold that part of what is going on in mere confabulation is that one is having a memory-experience in the absence of any such causal connection to a previous experience of a past event. If that is right, however, then the disjunctivist needs somehow to incorporate this insight into her preferred view of episodic memory. My suggestion is that she can do this by claiming that in her view, the kind of experience involved in genuine memory is essentially and therefore necessarily caused in the standard way by a prior experience of some past event, whereas the kind of experience involved in mere confabulation is essentially and therefore necessarily caused in a deviant or non-standard way.

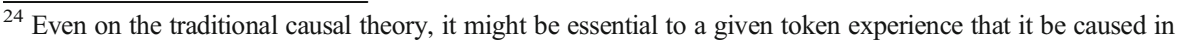
just the way it in fact was. This will be so if in general, the causal origins of an event are essential to it. However, it does not follow that any such token experience had to be caused in just the way it was just by virtue of being the kind of event that it is. Yet, that is what would be the case if the stronger, disjunctivist version of the causal theory were true.
} 
I conclude that there is good independent reason for the disjunctivist to endorse the kind of modified causal theory that I have sketched. What I want now to do, in the next section, is to explain how this theory can be put to work in responding to the arguments against disjunctivism that we considered above. ${ }^{25}$

\section{The Causalist Response}

We can think of the disjunctivist version of the causal theory just articulated as the conjunction of the following two claims:

(D1) It lies in the nature of genuine memory experiences to be standardly caused. That is, events of the sort involved in genuine memory are essentially produced in just that way.

(D2) It lies in the nature of confabulatory experiences to be non-standardly caused. That is, events of the sort involved in confabulation are essentially produced in just that way. ${ }^{26}$

Importantly, if both these claims are true, it follows the kind of memory-experience that a given brain state will be able to produce depends on the broader causal context in which it is embedded. In turn, this means that the causal chain that generates an experience effectively plays two different kinds of role. On the one hand, it plays a straightforwardly causal role in bringing the relevant memory-experience about. On the other hand, however, it also plays the role of background condition in determining what kind of experience the proximate brain state (occurring at the end of the long causal chain) is able to produce. In other words, not only does the causal chain generate the relevant experience in the straightforward causal way. In addition, the character of the causal chain plays the further role of a background condition determining what kind of experience the embedded brain state may generate. When the causal chain involved is standard, and thus connects the subject to a past experience of some suitable past event, this enables the brain state to produce an experience of the genuinely memorial kind, and disables it from producing an experience of the confabulatory kind. But when the causal chain involved is non-standard or deviant, and hence does not connect the subject in the right kind of way to a prior experience of some event in her personal past, this then enables the brain state to produce an experience of the confabulatory kind, and disables it from producing an experience of the kind involved in genuine memory. The kind of experience we end up with is therefore a function of the nature of the causal chain involved. Whether we end up with one kind of experience or the other depends upon whether the broader causal chain is standard or deviant. ${ }^{27}$

\footnotetext{
${ }^{25}$ One might also read the above in a conditional way: that is, one might read me as saying that if (D1) and (D2) are true, and incorporated into a disjunctivist setting, then disjunctivism can avoid the causal and screening off arguments. That would then give us good abductive reasons to accept (D1) and (D2). (Thanks to an anonymous referee for pointing this option out.)

${ }^{26}$ In effect, endorsing (D2) amounts to endorsing a causalist account of confabulation, albeit within a disjunctivist setting. For relevant literature developing similar accounts in a somewhat different setting see Berncker (2017b) and Robins (2019, 2020).

${ }^{27}$ Cf. Dennett (1987) for more general discussion of the way in which causal factors can sometimes play the kind of dual role.
} 
My main contention at this point is that in light of the above, it follows that if the disjunctivist accepts the form of causal theory captured by (D1) and (D2), then she ends up with the resources to answer the challenges posed both the casual argument and the screening off argument. Moreover, it emerges that she can do so in a unified way. To see this, let us reconsider these arguments in turn. ${ }^{28}$

Again, the causal argument depends on two main premises: Proximate Causes, and Same Cause, Same Effect. By Proximate Causes, we can imagine that some genuine memory $m$ has the same proximate cause as some mere confabulation $c$. By Same Cause, Same Effect, therefore, it follows that the proximate cause of $c$ also produces an experience of the same kind as $m$. However, the disjunctivist has to deny this, since on her view, the experience of the sort involved in genuine memory could not occur in a merely confabulatory case.

The thing to note is that given (D1) and (D2), we can now explain why Same Cause, Same Effect is false. According to that principle, proximate causes of the same kind always produce the same sort of immediate effect. In turn, at least given Proximate Causes, this then implies that the neural cause of a merely confabulatory experience must also produce an experience of the sort involved in genuine memory. However, the disjunctivist who accepts the casual theory that is captured by (D1) and (D2) can push back against this reasoning. By (D2), the proximate cause of any confabulatory experience must itself be produced in the deviant way. By (D1), however, the sort of experience involved in genuine memory must be produced in the standard and hence in a non-deviant way. Consequently, the brain state that produces the confabulatory experience could not produce an experience of the genuinely memorial kind. Therefore, Same Cause Same Effect is false, and the casual argument from confabulation fails.

What of the revised version of the causal argument, which depends on Proximate Causes and the weaker principle of Same Cause, Same Effect*? Again, this argument turns on a case involving veridical hallucination. By Proximate Causes, we can imagine we can imagine that some genuine memory $m$ has the same proximate cause as some veridical confabulation $c$. The worry, therefore, is that even if the disjunctivist insists (rightly) that a proximate brain state can only produce an experience of the sort involved in genuine memory when a suitable past event exists, Same Cause, Same Effect* will still imply that in the case of veridical hallucination, the subject has an experience of the genuinely memorial kind, since in that case, there does exist a suitable

\footnotetext{
${ }^{28}$ Before moving on, however, note that in accepting (D1) and (D2), the disjunctivist is not thereby redefining her view. Rather, she retains the same view as before, namely that: (A) Cases of genuine memory consist in acquaintance with past events, and (B) Cases of mere confabulation do not have this sort of nature. In accepting (D1) and (D2), one is adding commitments to the disjunctivist view, not redefining it. In particular, one comes to accept that experiences of the sort that (A) describes, i.e. genuine memories, must be caused in a certain manner, namely, the standard way by a suitable past event, whereas experiences of the sort that (B) describes, i.e. mere confabulations, must be caused in the non-standard or deviant way. Nor does accepting (D1) and (D2) undermine disjunctivism by introducing a common factor, i.e. a fundamental kind of mental state common to cases of genuine memory and mere confabulation alike. Note also that, in adding (D1) to the theory, one does not thereby imply that the acquaintance relation is a causal relation. One can hold that there are causal conditions on a relation being instantiated without denying that the relation is unanalysable and without holding that the relation is analysable in causal terms. Not, however, that I think there is anything wrong with the idea that acquaintance maybe a causal relation: in fact, this idea may offer further motivation for (D1). (Thanks to an anonymous referee for pressing me to clarify these issues.)
} 
past event for the subject to remember. Given (D1) and (D2), however, we can resist this line of reasoning. For, (D1) implies that a proximate brain state can only produce a genuinely memorial experience if it is embedded within a standard casual chain. By (D2), however, we know that the brain state that produces the veridical confabulation $c$ is not embedded in a standard causal context, but rather is a part of a deviant causal chain. Thus, a crucial background condition on the occurrence of a genuinely memorial experience, namely, that the causal context involve standard causation, is not met, and so Same Cause, Same Effect* no longer implies that the proximate brain state in the veridical confabulatory case will produce an experience of the genuinely memorial kind. In other words, the claim here is that Event Condition is false. That claim tells us that the only background condition on genuine memory is the existence of a suitable past event. On the causalist theory proposed here, however, this is not so, since in addition to a suitable past event, the right kind of causation must also be in play. This then implies that even given Proximate Causes and Same Cause, Same Effect*, we cannot infer that in cases of veridical confabulation one undergoes an experience of the sort involved in genuine memory.

Turn now to the screening off argument. Again, this goes as follows:

1. Even in cases of genuine memory, one undergoes the kind of experience in-volved in total confabulation.

2. If one undergoes the kind of experience involved in mere confabulation even in cases of genuine memory, then memory disjunctivism is false.

$\therefore$ Memory disjunctivism is false.

In section 3, I indicated that disjunctivists should reject premise 2. At this juncture, moreover, we are in a position to explain how. The argument for premise 2 turns on three main principles: Proximate Causes, Same Cause Same Effect*, and No Conditions. By Proximate Causes, we can imagine a genuine memory $m$ and a mere confabulation $c$ with the same proximate cause. By Same Cause Same Effect*, we know that the brain state that produces $m$ will also produce an experience of the same kind as $c$ so long as all of the relevant background conditions on the occurrence of an event of that kind are met. But No Conditions tells us that no further conditions beyond the occurrence of the right kind of brain state need be met in order for an experience of that kind to be produced. It therefore follows that even in the case of genuine memory, an experience of the kind involved in confabulating is going to be produced. But that establishes that premise 2 is true.

The crucial point is that given (D1) and (D2), we can push back against this argument. After all, (D2) implies that for a confabulatory experience to occur, the relevant brain state must be embedded in a deviant casual chain. Accordingly, it follows that contra No Conditions, the mere occurrence of the right kind of brain state is not enough to produce a confabulatory experience. Rather, the antecedent brain state has to be embedded within a deviant causal chain. By (D1), however, any brain state that produces a genuine memory will be embedded in a standard rather than a deviant causal chain. Accordingly, it 
emerges that a crucial background condition on the occurrence of a merely confabulatory experience can never be met in genuinely memorial cases. In turn, this means we can infer that premise 2 is false. Indeed, we can infer that it is never possible for a confabulatory experience to occur in a case of genuine memory. $^{29}$

Given the disjunctivist version of the causal theory sketched above, therefore, we can put forward a unified response to the causal argument and the screening off argument. Essentially, these arguments be understood as posing a pair of related challenges to the memory disjunctivist. Again, it seems possible for there to be two subjects such that one of them is genuinely remembering while the other is merely confabulating, whereby their respective experiences share the same proximate cause. The causal argument puts pressure on the disjunctivist by threatening to show that the proximate cause of the subject's confabulatory experience also causes an experience of the sort involved in genuine memory. Meanwhile, the screening off argument puts pressure on the disjunctivist by threatening to show that the proximate cause of the subject's genuine memory also causes an experience of the sort involved in confabulation. To deal with these two arguments, therefore, the disjunctivist must explain both (i) why the proximate cause of a merely confabulatory experience does not also produce an experience of the kind involved in genuine memory, and (ii) why the proximate cause of a genuine memory does not also produce an experience of the kind involved in mere confabulation. What I have argued is that by accepting (D1) and (D2), this explanatory challenge can be met. In particular, In particular, I have argued that the disjunctivist can meet this challenge by drawing on (D1) and (D2) by way of insisting that the causal context in which a given proximate brain state is embedded is crucial to determining the kind of memory-experience that it is able to cause. ${ }^{30}$

\footnotetext{
${ }^{29}$ What about cases of partial confabulation, wherein the subject is partly remembering and partly confabulating? It would be natural for a disjunctivist to interpret such cases as involving the simultaneous instantiation both of the genuinely memorial kind of experience and of the merely confabulatory experience. But how can this be if (D1) and (D2) rule out the possibility of these kinds of experience co-occurring? The answer, I think, is that we need to utilise a more fine-grained way of individuating kinds of memory-experience. The causal theory needs to claim that one cannot simultaneously have an experience of the kind involved in genuine memory $\mathrm{Km}$ and an experience of the kind involve in mere confabulation $\mathrm{Kc}$ whereby instances of these experience-types are phenomenally the same. To make this work, we need to associate various kinds of standard causation with phenomenally individuated kinds of genuine memory Km1, Km2...Kmn, and kinds of deviant causation with phenomenally individuated kinds of confabulation $\mathrm{Kc1}, \mathrm{Kc2}$, Kcn...The causal theory is then to be taken as implying that if any genuinely memorial experience $m$ and any confabulatory experience $c$ are of the same phenomenal kind, then $m$ must be caused in a way that is incompatible with the manner in which c must be caused, meaning that these types of experience can never be co-instantiated. Such a view delivers the result we need for responding to the screening off argument, while also allowing for partial confabulation.

${ }^{30}$ Accepting (D1) and (D2) thus means that distal factors - the presence of absence of the right kind of past event - serve to individuate experiential kinds. However, this was already a commitment of disjunctivism about the genuinely perceptual case. So I am adding nothing there: it was already part of the view that genuine memorial experiences are individuated in terms of relations to distal past events. What is new is that negative distal factors, involving either the absence of a suitable past event, or the presence thereof but then the wrong sort of causal chain ensuing, can serve to determine whether we have a case of confabulation. But this seems no more problematic than the idea, already built into standard disjunctivism, that distal factors serve to individuate experiential kinds. (And if it is more problematic, an argument would be needed.)
} 


\section{Conclusion}

In this paper, I have considered two related challenges to memory disjunctivism: the causal argument from confabulation, and the screening off argument. My central argument has been that by accepting a revised form of the traditional common factor causal theory, disjunctivists have the resources to respond to these arguments in a unified way. On the proposed view, genuine memories, by their very natures, have to be caused in the standard way, whereas mere confabulations, by their very nature, must be produced in a non-standard or deviant manner. As we have seen, given this kind of view, disjunctivists have the resources to undermine both the causal argument and the screening off argument. I submit, therefore, that disjunctivists about episodic memory should supplement their view by embracing precisely the causalist theory developed here.

Acknowledgements A version of this paper was presented at a conference on memory and perception at the Institut de Philosophie de Grenoble. Some of the material was presented earlier at a philosophy of mind work in progress seminar in Oxford and at a Brown University graduate seminar. My thanks to the participants on those occasions. Special thanks to Anita Avramides, Dominic Alford-Duguid, Umut Baysan, Chris Hill, Mike Martin, Kourken Michaelian, Adam Pautz, André Sant'Anna, Keith Wilson, and two anonymous referees for The Review of Philosophy and Psychology. The research for this paper was supported by an Early Career Fellowship awarded by the Leverhulme Trust.

Open Access This article is licensed under a Creative Commons Attribution 4.0 International License, which permits use, sharing, adaptation, distribution and reproduction in any medium or format, as long as you give appropriate credit to the original author(s) and the source, provide a link to the Creative Commons licence, and indicate if changes were made. The images or other third party material in this article are included in the article's Creative Commons licence, unless indicated otherwise in a credit line to the material. If material is not included in the article's Creative Commons licence and your intended use is not permitted by statutory regulation or exceeds the permitted use, you will need to obtain permission directly from the copyright holder. To view a copy of this licence, visit http://creativecommons.org/licenses/by/4.0/.

\section{References}

Aranyosi, I. 2020. Preteriception: Memory as past-perception, 1-28.

Bernecker, S. 2008. The metaphysics of memory. Dordrecht: Springer.

Bernecker, S. 2009. Memory: A philosophical study. Oxford: Oxford University Press.

Bernecker, S. 2017a. Memory and truth. In The Routledge handbook of philosophy of memory, ed. S. Bernecker and K. Michaelian. London: Routledge.

Bernecker, S. 2017b. A causal theory of mnemonic confabulation. Frontiers in Psychology 8.

Brewer, B. 2011. Perception and its objects. Oxford: Oxford University Press.

Burge, T. 2005. Disjunctivism and perceptual psychology. Philosophical Topics 33 (1): 3-17.

Byrne, A., and H. Logue. 2008. In 'Either/or', in disjunctivism: perception, action, knowledge, ed. A.

Haddock and F. Macpherson, 58-94. Oxford: Oxford University Press.

Campbell, J. 2002. Reference and consciousness. Oxford: Oxford University Press.

Campbell, J. 2010. Demonstrative reference, the relational view of experience, and the Proximality principle.

In New essays on singular thought, ed. R. Jeshion, 193-212. Oxford: Oxford University Press.

Child, W. 1992. Visual experience: the causal theory and the disjunctive conception. The Philosophical Quarterly 42 (168): 297-316.

Conduct, M. 2010. Naïve realism and extreme Disjunctivism. Philosophical Explorations 13 (3): 201-221.

Dancy, J. 1995. Arguments from illusion. The Philosophical Quarterly 45 (181): 421-438.

Debus, D. 2008. Experiencing the past: A relational account of recollective memory. Dialetica 62 (4): 405432 .

Dennett, D. 1987. Three kinds of intentional psychology. In The Intentional Stance. Cambridge: A Bradford Book.

Dretske, F. 1969. Non-epistemic Seeing. In Seeing and Knowing, 4-77. London: Routledge. 
Earle, W. 1956. Memory. The Review of Metaphysics 10 (1): 3-27.

Farkas, K. 2006. Indiscriminability and the sameness of appearance. Proceedings of the Aristotelian Society 106 (1): 207-227.

Fish, W. 2009. Perception, hallucination, and illusion. Oxford: Oxford University Press.

Foster, J. 1986. Ayer. London: Routledge and Kegan Paul.

Foster, J. 2000. The nature of perception. Oxford: Oxford University Press.

Grice, P. (1961) The causal theory of perception. Proceedings of the Aristotelian Society 35 (1): 121-152.

Hawthorne, J., and Kovakovich, K. 2006. Disjunctivism. Proceedings of the Aristotelian Society 8(1): 145183.

Hellie, B. 2013. The multidisjunctive conception of hallucination. In Hallucination, ed. F. Macpherson and D. Platchia, 149-174. MA: The MIT Press.

Johnston, M. 2004. The obscure object of hallucination. Philosophical Studies 120 (1/3): 113-183.

Langsam, H. 1997. The theory of appearing defended. Philosophical Studies 87 (1): 33-59.

Lewis, D. 1980. Veridical Hallucination and Prosthetic Vision. Australasian Journal of Philosophy 58 (3): $239-249$.

Logue, H. 2013a. Good news for the Disjunctivist about (one of) the bad cases. Philosophy and Phenomenological Research 86 (1): 105-133.

Logue, H. 2013b. What should the Naïve realist say about total hallucinations? Philosophical Perspectives 26 (1): 173-199.

Logue, H. 2015. Disjunctivism. In The Oxford Handbook of Philosophy of Perception, ed. M. Matthen, 198214. Oxford, Oxford University Press.

Martin, M.G.F. 1992. The Content of Experience, ed. D. Phil: University of Oxford.

Martin, M.G.F. 2004. The limits of self-awareness. Philosophical Stuies 120 (1/3): 37-89.

Martin, M.G.F. 2006. On being alienated. In Perceptual experience, ed. T.Z. Gendler and J. Hawthorne, 355407. Oxford, Oxford University Press.

Martin, M.G.F. 2001. Out of the past: Episodic recall as retained acquaintance. In Time and memory, ed. C. Hoerl and T. McCormack, 257-284. Oxford University Press.

Martin, M.G.F. 2013. Shibboleth: Some comments on William Fish's perception, illusion and hallucination. Philosophical Studies 163 (1): 37-48.

Martin, C.B., and M. Deutscher. 1966. Remembering. Philosophical Review 75 (2): 161-196.

Michaelian, K. 2016. Confabulating, Misrembering, Relearing: The Simulation theory of memory and unsuccessful remembering. Frontiers in Psychology 7 (1857). https://doi.org/10.3389/fpsyg.2016.01857.

Moran, A. 2019a. Naïve realism, causation and hallucination: A new res-ponse to the screening off problem. Australasian Journal of Philosophy 97 (2): 368-382.

Moran, A. 2019b. Naïve realism, seeing stars, and perceiving the past. Pacific Philosophical Quarterly 100 (1): 202-232.

Moran, A. (manuscript-a). Disjunctivism and the casual conditions of hallucination, manuscript-a.

Moran, A. (manuscript-b). Minimal disjunctivism and the screening off problem.

McDowell, J. 1994. The content of perceptual experience. The Philosophical Quarterly 44 (175): 190-205.

McDowell, J. 2010. Tyler Burge on disjunctivism. Philosophical Explorations 13 (3): 243-255.

Nudds, M. 2013. Naïve realism and hallucinations. In Hallucination, ed. F. Mac-Pherson and D. Platchia, 149-174. MA: The MIT press.

Pautz, A. 2011. Can Disjunctivists explain our access to the sensible world? Philosophical Issues 21 (1): 384 433.

Pautz, A. n.d. (manuscript) 'How visual experience reaches to the world', m.s. draft.

Robins, S. 2019. Confabulation and constructive memory. Synthese 196 (6): 2135-2151.

Robins, S. 2020. Menumonic Confabulation. Topoi 39 (1): 121-132.

Robinson, H. 1985. Essays on Berkeley: A Tercentennial Celebration, ed. John Foster and Howard Robinson, 163-186. Oxford: Oxford University Press.

Robinson, H. 1994. Perception. London: Routledge.

Russell, B. 1912. Problems of philosophy. London: Routledge.

Schwarz, A. 2018. Memory and disjunctivism. Essays in Philosophy 19 (2): 1-17.

Searle, J. 2015. Seeing things as they are: a theory of perception. Oxford University Press.

Siegel, S. 2004. Indiscriminability and the phenomenal. Philosophical Studies 120 (1/3): 37-89.

Siegel, S. 2008. The epistemic conception of hallucination. In Disjunctivism: perception, action, knowledge, eds. MacPherson, F. \& Haddock, A. Oxford: Oxford University Press: 206-223.

Smith, A.D. 2008. Disjunctivism and discriminability. In Disjunctivism: perception, action, knowledge, eds. MacPherson, F. and Haddock, A., Oxford: Oxford University Press: 182-203. 
Snowdon, P.F. 1981. Perception, vision and causation. Proceedings of the Aristotelian Society (New Series) 81 (1): $175-192$.

Snowdon, P.F. 1990. The objects of perceptual experience. Proceedings of the Aristotelian Society 64 (1): 121-166.

Soteriou, M. 2005. The subjective view of experience and its objective com-mitments. Proceedings of the Aristotelian Society (New Series) 105 (1): 177-190.

Sturgeon, S. 1998. Visual Experience. Proceedings of the Aristotelian Society 72 (2): 179-200.

Travis, C. 2011. Desperately seeking భ. Philosophical Issues 21 (1): 505-557.

Tye, M. 2007. Intentionalism and the argument from no common content. Philosophical Perspectives 21 (1): 589-613.

Tye, M. 2009. The admissible contents of visual experience. The Philosophical Quarterly 59 (263): 541-562.

Tye, M. 2014. What is the content of a hallucinatory experience? In Does perception have content? ed. B. Brogaard, 292-308. Oxford: Oxford University Press.

Publisher's Note Springer Nature remains neutral with regard to jurisdictional claims in published maps and institutional affiliations. 